International Journal of Child, Youth and Family Studies (2011) 2.1: 233-262

\title{
THE CORRELATES OF YOUTH VIOLENCE: EVIDENCE FROM THE LITERATURE
}

\begin{abstract}
Alan W. Leschied
Abstract: This review provides a general presentation of the factors that are linked to youth violence. In general, these risk factors can include any of the following: pregnancy and delivery complications, emotion-related disorders, hyperactivity, concentration problems, restlessness, risk taking, aggressiveness, early initiation into violent behaviour and beliefs, and attitudes supportive to violent behaviour. What can increase our accuracy of prediction for youth violence is an appreciation of the systemic factors that interact with these individual risk factors. These can include factors within the family including: early family conditions related to poverty, abuse, a generally poor relationship between child and parent, and parental criminality. Peers also play a role in rewarding behaviour and attitudes supportive of youth violence. The implications for knowledge with respect to these correlates are highlighted in a review of promising programs that address youth violence.
\end{abstract}

Key Words: youth, violence, descriptors, predictors, gender

Acknowledgement: This review was made possible with funding support from The Centre of Excellence in Children's Mental Health, Children's Hospital of Eastern Ontario, Ottawa, Ontario, Canada. Comments on earlier drafts of this review from Dr. Ian Manion were of particular benefit and are gratefully acknowledged.

Alan W. Leschied, Ph.D. is a Professor in the Faculty of Education at the University of Western Ontario, London, Ontario, Canada. Telephone: (519) 661-2111, ext. 88628. E-mail: leschied@uwo.ca

Canadian Research Perspectives for Youth at Risk for Serious and

Violent Offending: Implications for Crime Prevention Policies and Practices 
International Journal of Child, Youth and Family Studies (2011) 2.1: 233-262

\section{The general correlates of youth violence}

Violence in the general society remains a relatively rare event or, in other words, it is a low base rate phenomenon, which is to say that it simply does not happen very often. Hence, the prediction of such relatively rare events is a challenge for researchers in either overestimating the relationship between a predictor and the committal of violence, referred to as false positive predictions, or underestimating the relative strength of a predictor, referred to as false negative predictions. In other words, research is drawn from the general case and caution is always expressed for translating the significance of such findings to specific instances. In addition, predicting a violent incident, even knowing the risk within the young person, will still require a precipitating event that will trigger the violent act. Hence what is also necessary in order to increase the likelihood of an accurate prediction is an understanding of the contexts or circumstances that can increase the likelihood of violence. There are both direct and indirect circumstances that relate to the likelihood of the committal of a violent act by a young person. As Gilgan (1999) notes, the direct contextual variables can include any one of the following:

1. A preoccupation with violence

2. Access to means (i.e., weapons)

3. Psychological vulnerability

4. History of violence within the family of origin

5. A pattern of glorifying violence

Indirect indicators or circumstances that can influence violence potential include:

1. Being emotionally closed

2. Unshared anger and grief

3. A history of antisocial behaviour that has been non-violent in the past

4. Chemical abuse

5. Self-injurious behaviour

6. Signs of cumulative stress

With these facts in mind, this section will summarize the general correlates of child and youth violence. It will be organized around those factors that are considered within the individual and those that are related to the systems that surround children and youth, namely families, peers, school, and the media.

Canadian Research Perspectives for Youth at Risk for Serious and

Violent Offending: Implications for Crime Prevention Policies and Practices 
International Journal of Child, Youth and Family Studies (2011) 2.1: 233-262

\section{Individual factors}

Numerous studies have now reported on a number of individual risk factors that have been identified linking individual characteristics within the youth to the committal of violence. Risk for violence occurs at all developmental points in the life of the child or youth. Hawkins et al. (2000) have provided amongst the most useful summaries of these risk factors for violence in the context of when in the life course of the young person they occur. These can include any number of the following: pregnancy and delivery complications, emotional disorders, hyperactivity, concentration problems, restlessness, risk taking, aggressiveness, early initiation into violent behaviour, and beliefs and attitudes favourable to violent behaviour. What is missing from this review is the differential strength of each predictor. In addition, while these risk factors have been shown to predict violence, many of them also predict general criminogenic behaviour as well. What can increase the accuracy of violence prediction, however, is an appreciation of the context or systemic variables that can increase the accuracy of the prediction. The following sections review the major systemic predictors of risk for youth violence.

\section{Systemic factors}

Family. Families play a differentially powerful role in shaping the behaviour and values of their children. Within a developmental framework, and in the context of appreciating the influence of families on aggressive and violent behaviour in their children and adolescents, the most meaningful way to characterize this influence is, again, within a developmental perspective. That is, what family influences at what ages and stages of their children are predictive of future violent behaviour?

Lipsey and Derzon (1998) have offered a useful summary of the family-related predictors of youth violence, separating those predictors that are relevant in the lives of children ages 6 to 11 and those relevant to an older age group, 12 to 14 years. For the younger age group, the strongest predictors include family socioeconomic status and antisocial orientation of the parents. Weaker predictors, yet still significant, were related to parent-child relations, coming from a "broken" home, and having abusive parents. For the older age group, some of the same predictors were in evidence: parent-child relations, having parents who themselves were antisocial and coming from a "broken" home, family socioeconomic status, and having abusive parents. It would therefore appear that early family conditions related to poverty, abuse, and a generally poor relationship between child and parent are related to later violence. However, these conditions within the family do not operate in isolation. In the absence of strong family ties that reinforce prosocial and non-violent ways of coping, young people will seek out associations with peers who will, in some respects, fill a vacuum of belongingness through the types of associations that are established.

Canadian Research Perspectives for Youth at Risk for Serious and 
International Journal of Child, Youth and Family Studies (2011) 2.1: 233-262

Peers. There is an extensive literature related to the importance of peer associates in promoting youth antisocial and violent behaviour. From a developmental perspective, the value of peers influencing individual adolescent behaviour has been identified as one of the strongest risk factors for adolescents, second only to personal values and beliefs supportive of violence. It would appear that not only the association with negative peers that legitimatize and reinforce antisocial beliefs and values around violence, but the isolation from adolescents who represent more prosocial non-violent beliefs is what lies at the basis of the strength of this factor. This is particularly the case when viewed from the perspective of youth who are immersed within a gang culture where the values related to supporting violence are pervasive. Youth gang members, as opposed to youth who hold preference for the association with antisocial peers but who are not organized within a gang culture, hold particularly strong negative peer associates. These are young persons who have met with limited success socially and academically and have difficulty finding meaningful ways in organizing their time. As summarized in a previous report for the Ministry of Children and Youth Services (Leschied, 2007):

Affiliation within gangs meet an individual youth's needs for power, affiliation, selfesteem, socialization, and, what can only be characterized as, creating a "feeling of family" and a sense of belonging. There is some belief that as youth may continue to feel marginalized and disconnected from the mainstream with family structures changing and school/work becoming increasingly challenging for certain segments of the province's youth, the formation of gangs may continue to be an attractive option.

Peers can form the basis for much of a marginalized adolescent's values that can influence the perceived rewards attached to behaving violently. The challenge of providing effective community-based intervention for gang violence is a significant one. Recent reviews of the literature produced for both Ontario's Ministry of Children and Youth Services (Leschied, 2007) and by the First Nations University of Canada along with the University of Saskatchewan (Lafontaine, Ferguson, \& Wormith, 2005) will be of more than passing relevance for appreciating effective evidence-based practice for gang-related interventions.

School. Schools offer one of the most significant socialization contexts for youth and hence hold significant potential to affect a child's life course (Ladd, Buhs, \& Troop, 2002). Unsafe, cliquish environments in schools can contribute to a difficult school experience for some students, especially for a subgroup who experience frequent physical and verbal harassment (Rusby, Forrester, Biglan, \& Metzler, 2005). This subgroup is more likely to exhibit problems in high school reflected in aggressive behaviours, antisocial peer associates, and numerous mental health disorders such as alcohol use, and psychological distress reflected in low self-esteem, insecurity, depression, anxiety, and suicide (Rusby et al., 2005; MacKay \& Sutherland, 2006; Reynolds, 2003; Rigby, 2003).

Canadian Research Perspectives for Youth at Risk for Serious and Violent Offending: Implications for Crime Prevention Policies and Practices 
International Journal of Child, Youth and Family Studies (2011) 2.1: 233-262

Heng, Leschied, and Killip (2009) indicate that perceiving the school as unsafe due to the threat of violence is linked to anxiety and phobic responses, harm to students' mental and physical health, and ultimately to the avoidance of school altogether. Reynolds (2003) suggests that if students fear for their safety, they may avoid areas of their life in which this safety is threatened. When the setting being avoided is school, students' learning and their pursuit of an education is also compromised. The National Center for Education Statistics (2005) noted that victims of bullying were more likely than non-victims to report receiving failing grades. Hence what has emerged is the study of the major predictors for school-based violence, the impact of violence occurring within the school context, and what constitutes more versus less safe schools that can promote violence-free learning environments that also address student mental health concerns (Warner, Weist, \& Krulak, 1999).

\section{Culture: The Influence of Media}

[T]aken as a whole, the past 50 years of research on human aggression suggests that habitual aggressive behavior in young humans is to a great extent learned from the child's early interactions with the environment. (Huesmann et al., 1997, p. 183)

To this point, family, peers, and school have been highlighted as important systemic factors that aid in the understanding of risk as it relates to the perpetration of youth violence. In the context of mental health disorder, the literature thus far indicates that certain factors can both create the conditions for children and youth such that they are more likely to experience mental health disorder and are also linked in ways that increase the likelihood that certain youth will act in aggressive or violent ways. In other words, it is how individuals, children and youth, interact with their surroundings in the context of having a mental health disorder that aids in both the prediction as well as the understanding of the link between mental health and youth violence. An additional systemic context in which to appreciate youth violence and mental health disorder is reflected in the influence of violent media on child and youth violence, attitudes, and behaviour.

The role of media is a legitimate area of concern in a review of violence and mental health given its predominance in the lives of children and youth. There is also a substantial body of knowledge that has examined its impact on the conditions under which certain youth act in violent ways, which is linked to their consumption of violence in the media.

Some of the hallmark studies, which addressed the importance of observational learning and aggression, occurred almost 50 years ago. Since that time, there has been a refinement in examining the nature of how violence in the media impacts children and adolescents. And while most of the knowledge base in this area remains correlational, the convergence of findings from

Canadian Research Perspectives for Youth at Risk for Serious and

Violent Offending: Implications for Crime Prevention Policies and Practices 
International Journal of Child, Youth and Family Studies (2011) 2.1: 233-262

different studies along with the strength of associations reported, suggest there is now an acceptance that certain young people will be more adversely affected (i.e., demonstrate more aggression) with greater exposure to violent media. In the prestigious journal Psychological Science in the Public Interest, distinguished researchers (Anderson et al., 2003) including Leonard Berkowitz and Rowell Huesmann summarized their review of the evidence regarding the impact and role of violence in the media:

Research on violent television and films, video games, and music reveals unequivocal evidence that media violence increases the likelihood of aggressive and violent behavior in both immediate and long-term contexts. (p. 311)

In a review of both correlational and experimental studies, this review identified not only the impact of witnessing violence that is promoted as entertainment, but also the characteristics within the observation of violence in music, films, television, and interactive games that influence children and youth to act out violently. This review suggests that it is a combination of imitation learning, the "priming” of aggressive cognitive schemas that make more readily accessible violent images and actions, arousal and excitation, and emotional desensitization.

It is also germane to a review of childhood and youth mental health disorders and violence to acknowledge that there is a differential impact of viewing media violence. Simply, certain observers are more susceptible to the influence of watching such violent content compared to others. For example, age of the viewer, gender, and identification with the violent character being depicted are all factors that will influence media's impact on youthful viewers. There is also research reporting on the interaction of media violence with certain psychological characteristics of the viewer. Huesmann, Moeski, and Podolski (1997), noted that the mental health characteristics of children and youth affected their susceptibility to the impact of the violence being watched. Specifically, youth who were characterized as more aggressive prior to consuming violent media acted out their violent tendencies to a greater extent. This was particularly the case for boys where emotional disorder characterized youth who were more aggressive and reacted more violently following the observation of violent media content, relative to a group of young males who were within normal limits on scales assessing psychological adjustment.

\section{Community factors that mediate the extent and nature of youth violence}

Generally speaking, social disadvantage will be a predominant predictor in appreciating a youth's risk for either or both mental health disorder and violence (Aneshenel \& Sucoff, 1996). These predictors will rest on the youth's perception as to the degree of safety, social stability, and social cohesion that exists within the immediate community. Hence transient communities, communities where there is a high level of openly expressed violence, and communities where

Canadian Research Perspectives for Youth at Risk for Serious and

Violent Offending: Implications for Crime Prevention Policies and Practices 
International Journal of Child, Youth and Family Studies (2011) 2.1: 233-262

there is not a shared appreciation for academic or vocational attainment will be perceived as less stable and more threatening. Locating where a youth lives can influence the extent to which that person experiences either mental health or violent outcomes. Further, while it is limited, there are reports comparing the levels of distress and violence for youth in urban and rural communities.

Given the above findings with respect to the perception of social stability, it may be a surprise to note the findings from one large-scale study suggesting that male youths coming from rural communities present more significant problems in the context of experiencing higher unemployment rates, lower educational attainment levels, and greater use of illegal substances, as well as per capita higher arrest rates for violence. However this is not to suggest that urbanbased youth perceive their communities as being risk-free. Rather it may be that the risks for urban-based youth related to mental health and violence are unique relative to rural-based youth. Urban-based risk factors for youth violence include extreme poverty, community disorganization, high rates of transitions, criminal subculture, and the availability of drugs and weapons (Swenson, Henggeler, Taylor, \& Addison, 2005).

\section{Mental health correlates of youth violence}

[N]o matter how many social and demographic factors are statistically taken into account, there appears to be a greater-than-chance relationship between mental disorder and violent behavior. Mental disorder [is] a statistically significant risk factor for the occurrence of violence. (Monahan, 1997)

Dating back to the early 1980s, Dr. Dan Offord and his associates at McMaster University reported in the Ontario Child Health Study estimates that one in five of Ontario's children and adolescents will experience a mental health or behavioural disorder sufficient in degree to require some form of outside intervention (Offord, Boyle, Fleming, Blum, \& RaeGrant, 1989). This estimate has been replicated in other countries suggesting a relatively stable cross-cultural rate of mental health disorder in the child and youth population of 20 per cent for children and youth ages 0 to 16 . The most common disorders identified include depression and conduct disorder. The question, in the context of this review, relates to the literature reporting on the crossover of children and youth who experience a mental health disorder and who also display violent or aggressive tendencies.

While the rate of $20 \%$ of the child and youth population who experience some form of mental health disorder is a stable cross-cultural estimate, there is variability within this estimate as to the severity of the disorder(s). Typically, mental disorder with significant impairment is reflected in $11 \%$ of the overall one in five, with extreme disorder reflected in $5 \%$ (Osenblatt, 2001). So the question then is this: Within this group of children and youth who experience more extreme impairments due to mental health disorder, who are those youth, who have a tendency to

Canadian Research Perspectives for Youth at Risk for Serious and

Violent Offending: Implications for Crime Prevention Policies and Practices 
International Journal of Child, Youth and Family Studies (2011) 2.1: 233-262

act violently? There are several methodologies that have been used to address this issue. The first is the group of studies that examine prospectively what the estimate of mental health disorder in children and youth is, and the percentage of this group who are subsequently involved in the commission of violence. The second methodology is the retrospective study of youths who have committed a violent act, been arrested, and then, through psychological testing and detailed history taking, are described as those youth who have had or currently experience a mental health disorder.

Prospective studies related to mental health disorder and violence. Prospective studies are more generalizable to other populations relative to retrospective studies, since they begin from a more inclusive understanding of the population under study. Generally then, findings from such studies tend to be relevant for readers wishing a more general appreciation of the prevalence of youth violence and mental health disorder. One study is representative of findings that relate prospectively to the prevalence of violence and mental health disorder in a birth cohort, this one occurring in England (Arsenault, Moffitt, Caspi, Taylor, \& Silva, 2000). In a sample of slightly less than 1,000 children, participants were tracked to their 21st birthday to record the incidence of violent behaviours. Several noteworthy findings emerged from this study. First, approximately $2 \%$ of the original sample met diagnostic criteria on the DSM-III-R (the sample was originally assessed in 1973). In descending order, the most prevalent mental health disorders were alcohol dependence, marijuana dependence, and schizophrenia. Participants who met the diagnostic criteria for child and youth mental health disorder reflected $20 \%$ of the sample, who committed at least one violent act. However, taken together they accounted for over half of all of the violent crimes reported. And, of the differential diagnostic categories, the groups accounting for the greatest extent of violence in descending order were: marijuana dependence, $3.8 \%$; schizophrenia, $2.5 \%$; and alcohol dependence, $1.9 \%$. The conclusions of these authors:

In the age group committing the most violent incidents, individuals with mental disorders account for a considerable amount of violence in the community. Different mental disorders are linked to violence via different core explanations. (Arsenault et al., 2000, p. 979)

As previously stated, there is a significant overlap in the conditions that account for violence with those that also account for mental health disorder. For example - and a more complete summary of this issue will occur in a later section of this report under the heading the cycle of violence - exposure to violence within a child or youth's family of origin has both the impact of modelling violence as well as being a risk factor in promoting emotional disorder such as depression. Durant, Barkin, Kreitzer, and Krowchuc (2001) noted that while adolescents who are exposed to violence have a greater likelihood of resorting to violence to resolve interpersonal conflicts, acquire possessions, and achieve goals, such exposure is also associated with higher

Canadian Research Perspectives for Youth at Risk for Serious and 
International Journal of Child, Youth and Family Studies (2011) 2.1: 233-262

scores on depression and increases in the consumption of illegal substances.

In addition, a recent meta analysis by the author along with colleagues at the University of Western Ontario and the Center for Addiction and Mental Health provides a review of prospective studies in the prediction of later youthful offending including violence (Leschied, Chiodo, Nowicki, \& Rodger, 2008). Two important outcomes were identified in this review. The first was that within the set of predictors, childhood and adolescent factors that rated most highly included: a variety of behavioural concerns such as the early identification of aggression, attentional problems, motor restlessness, and attention seeking; emotional concerns consistent with depression reflected in withdrawal, anxiety, self-deprecation, and social alienation; family characteristics such as a variety of negative parenting strategies including coerciveness, authoritarian behaviours, lack of child supervision, and family structure such as witnessing violence, interparental conflict, and poor communication. The second major finding was that as the negative life circumstance occurred later for the adolescent, the predictor was more accurate for future antisocial and violent behaviour, extending into adulthood.

Retrospective studies related to mental health disorder and violence. Retrospective studies use as their starting point an already defined group, in the present case youth who have committed or been arrested for committing a violence-related offence. The information generated from these studies provides important clues related to this subgroup of youth. However, there is a tendency in such retrospective analysis to overestimate the prevalence of mental health and violence in youth. Hence caution should always be used in appreciating the significance of such data. Notwithstanding this caution, it will come as little surprise to learn that the crossover of mental health disorder with youth who have been arrested for violence-related offences is high relative to those who are arrested and do not meet a diagnostic criteria for the presence of such a disorder. Teplin, Abram, McClelland, Dulcan, and Mericle (2002) reported the following with their youth detention-based sample:

$60 \%$ of males and more than two-thirds of females met diagnostic criteria and had a diagnosis-specific impairment for one or more psychiatric disorders. Half of the males and almost half of the females had a substance use disorder, and more than $40 \%$ of males and females met criteria for disruptive behaviour disorders. Affective disorders were also prevalent, especially among females; more than $20 \%$ of females met criteria for a major depressive episode. Rates of many disorders were higher among females. (p. 1133)

The significance of gender reflected in such data will be further explored in a subsequent section in this report detailing gender as an important factor in understanding the link between mental health disorder and youth violence. Relevant to the above findings here however is the representation of the extent of mental health disorder in youth who appear in the youth justice

Canadian Research Perspectives for Youth at Risk for Serious and

Violent Offending: Implications for Crime Prevention Policies and Practices 
International Journal of Child, Youth and Family Studies (2011) 2.1: 233-262

system because of the commission of a violent offence. Further, MacKinnon-Lewis, Kaufman and Frabutt (2002) suggest, "Youth involved with the juvenile justice system frequently have more than one co-occurring mental and substance use disorder” (p. 359).

Several considerations bear attention in this context. Youth come into the youth justice system for many reasons. Obviously youth appear because they have, in the context of this review, been arrested for the committal of violence-related offence(s). Their offence drives their appearance in court and subsequent placement within the range of dispositional alternatives open to the court. However it may also be that youth are "managed" in the justice system because of the lack of resources in other aspects of the children's service delivery system, either through the children's mental health or child welfare systems. A full discussion regarding how the children's service delivery system manages the mental health needs of youth is beyond the scope of this review and interested readers can refer to the more detailed study in Judy Findlay's (2002) Crossover Kids authored through the Ontario Office of the Child Advocate. Suffice at this point to appreciate that the representation of the extent of youth with mental health disorders who appear in the youth justice system as the result of violence-related offences can also be a caveat not only of the crossover of challenges that certain youths present - violence and mental health disorder - but also how the systems identify and are organized to meet the needs of these youth.

In addition, the literature relating risk factors for mental health disorder and youth violence and general antisocial behaviour reflects a high degree of overlap. One epidemiologic study of risk factors associated with youth psychiatric disorder included the following list of factors: sociodemographic factors including parental income and family structure; parental management practices reflected in the use of physical discipline; the quality of the family environment related to parental discord and marital quarrelling; negative life events that result in extreme stress; and a history of psychiatric disorder in parents (Goodman et al., 1998). Mapped against this list of risk factors for mental health disorder in youth, is the following list of risk factors for violence in youth: early identified nervousness, anxiety, and worry; early signs of aggressiveness; early initiation into violence and general delinquency; parental criminality reflected in a high tolerance within the family for violence in general; child maltreatment; poor family management reflected in inconsistent discipline or the use of physical child management practices; negative parent-child involvement and interaction; poor family bonding; high levels of family conflict and marital discord; stressful family events; low academic attainment and truancy; peer and sibling delinquency; availability of drugs; neighbourhood adults involved in crime and violence; exposure to racial prejudice; and poor community organization and low neighbourhood attachment (Hawkins et al., 1998).

The conclusion drawn from the review of the comorbidity regarding mental health disorder and violence suggests there is considerable overlap in the conditions under which some children and youth who develop a mental health disorder also display some form of violent

Canadian Research Perspectives for Youth at Risk for Serious and

Violent Offending: Implications for Crime Prevention Policies and Practices 
International Journal of Child, Youth and Family Studies (2011) 2.1: 233-262

behaviour. Still, while the overlap of these conditions is significant, most children and youth who experience a mental health disorder do not proceed to develop beliefs favourable in the use of violence. In certain cases, such as reflected in children and youth who are the victims of violence themselves, the emergent violence displayed can be readily understood within the context of the cycle of violence. Other violent outcomes related to a child's mental health status would seem not to be as clear, and for this, it is important to consider the circumstances that the child interacts with as reflected in their family status, peer associates, and school belongingness and achievement that together may help explain violent outcomes. This is an obvious area for future research in appreciating those children who are not only at risk for mental health disorder but also for violence as well.

\section{Substance use and youth violence}

A number of studies cited already have identified the relevance of substance use with violence. It will therefore come as no surprise that there is a strong link between the use of illegal substances and alcohol and antisocial or violent behaviour among young people. Indeed an early study examining this relationship suggested that the link created a "clear pathway" between substance use and violence (Huizinga, Menard, \& Elliott, 1989). Yet, not all young people who consume illegal drugs or use alcohol behave in antisocial or violent and aggressive ways. A recent study on substance abuse in Canada indicates, "some teens may be self-medicating to cope with toxic environments, untreated trauma, and underlying psychological conditions” (Canadian Centre on Substance Abuse, 2006). The result could be that certain at-risk youth with mental health disorder who resort to heavy drug use may be exacerbating their condition that in part could appear as a heightened risk for violence. Information such as this suggests that the relationship between drug and alcohol consumption and adolescent violence is more complex than might first appear. Indeed, when we look at this literature, we find that the consumption of certain drugs or alcohol under specified conditions will influence not only the likelihood of the committal of a violent act, but is also revealing of the link to specific violent acts, such as dating violence and sexual assault.

The link between substance use and violence. First, as previously stated, the stable estimate of mental health disorder in the child and youth population is consistently reported as $20 \%$. Within this percentage the representation of disorders is: anxiety disorders, $13.0 \%$; disruptive disorders, 10.3\%; mood disorders, 6.2\%; and substance use disorders, $2.0 \%$. Hence, substance use is the fourth leading mental health disorder identified within the child and youth population. Second, research suggests that the use of illegal substances is imbedded in a series of early life circumstances for children and adolescents. These typically include coercive family processes, social stress, poverty, poor academic outcomes, and social disadvantage (Patterson, Reid, \& Dishion, 1992). Noteworthy, when referencing substance use, a distinction is made between experimental occasional users, and heavier more constant users. Those youth more

Canadian Research Perspectives for Youth at Risk for Serious and

Violent Offending: Implications for Crime Prevention Policies and Practices 
International Journal of Child, Youth and Family Studies (2011) 2.1: 233-262

closely aligned with heavier, constant drug use are more likely to be involved in antisocial and violent behaviour.

Again it is difficult to disentangle the effects of substance use and violence, as many of the predictors of youth violence are also characteristic of substance users. These include, inconsistent parental discipline and harsh, punitive parental practices, low parental monitoring of their child/youth's behaviour and whereabouts, deviant peer associations, depression, low selfesteem, and poor academic achievement (Dishion, Capaldi, \& Yoerger, 1999). In addition, the illegal use of substances and the committal of violence is also imbedded within the youth's social and academic context. For example, in one large study in Washington State, researchers identified that not only is substance use linked to youth violence but it is also part of an array of other later risk factors such as poor academic performance, likelihood for dropping out of school, and poverty (Mandell, Hill, Carter, \& Brandon, 2002). The implications of findings such as these speak to the need for interventions that are multifaceted and include all aspects of the youth's community. As summarized in the Washington State analysis of findings, "If schools and communities are concerned about improving achievement, they must address both attitudes and behaviors related to substance use and violence”

The link between substance use and specific forms of violence. There is also research linking the use of substances and alcohol use to specific forms and contexts for youth violence. Here, the literature focuses on dating violence and sexual assault.

It is estimated that approximately $20 \%$ of young women to the age of 18 years will be either physically and/or sexually assaulted within the context of a dating relationship (Silverman, Raj, Mucci, \& Hathaway, 2001). Further, compared to males who may be victimized, females report higher levels of severe violence and more severe physical and emotional reactions to that violence (Molidor \& Tolman, 1998). Of relevance in this section relating substance and alcohol abuse to adolescent violence is the consistent finding that the relationship of dating violence and unwanted sexual involvement is highly related to drug and alcohol consumption. In numerous studies, drugs and alcohol have been shown to increase risk in both college age and high school age youth and has been identified as the main reason for unwanted sexual activity for both male and female victimization (Gover, 2004).

\section{Gender}

Similar to other countries reporting data related to gender and violence, Canada too shares an increasing violent crime rate for adolescent girls. Recent evidence from Statistics Canada suggests that the violent crime rate for girls has doubled over the past ten years, currently reflecting approximately $8 \%$ of the officially reported total adolescent violent crime rate. In the United States the general crime rate for adolescent girls has increased to a similar extent and is

Canadian Research Perspectives for Youth at Risk for Serious and

Violent Offending: Implications for Crime Prevention Policies and Practices 
International Journal of Child, Youth and Family Studies (2011) 2.1: 233-262

increasing at a much higher rate than for any other segment of the population (Henington, Hughes, Cavell, \& Thompson, 1998) with the percentage of girls involved in violent crime increasing by 103\% during the period from 1984 to 1993 . However, it should be remembered that adolescent boys continue to commit the vast majority of violent crime with a prevalence ratio compared to adolescent girls of from 3:1 to 12:1 depending on the exact type of violent offence reported (Borduin \& Schaeffer, 1998). Why is the issue of gender salient in a review of mental health and violence?

While males are involved in the majority of incidents of physical aggression, the increase of female violence reflects a broadening of the definition of what constitutes violence. And, as the definition of what constitutes violence is broadened, the data begins to reflect something quite different in terms of the representation of girls in violence categories. Everett and Price (1995) suggest that while girls are lower in rates of school violence when compared to boys when violence is defined as overt aggression, girls are proportionally more likely to appear in the data when verbal threats and intimidation are included. Crick (1996) suggests that, "the degree of aggressiveness exhibited by girls has been underestimated in prior studies, largely because forms of aggression relevant to girls' peer groups have not been assessed” (p. 719). And, as recent studies have suggested, the presence of indirect forms of female aggression is related to the expression of physical forms of violence as well (Cummings \& Leschied, 2002).

Bjorkqvist and his colleagues in Finland contributed significantly to the understanding of girls' aggression within this broader definition. These researchers suggest that violence reflects not only an act, but also an intention. The focus on physical aggression reflects a male perspective; female indirect aggressive tendencies focus on the disruption of relationships. In this context, "instigators who manipulate others to attack the victim or, by other means, make use of social structures in order to harm another person,” are seen as acting in aggressive ways (Bjorkqvist, Osterman, \& Kaukiainen, 1992).

There are unique contributors in appreciating gender in the context of adolescent violence within a mental health perspective. In a review provided to the Solicitor General of Canada, the author along with a research team from the Universities of Western Ontario and Toronto reviewed the literature comparing risk factors for adolescent female versus male violence (Leschied, Cummings, Van Brunschot, Cunningham, \& Saunders, 2000). Unique to the studies on comorbidity with violence and risk with boys, girls who behave aggressively report higher levels of depression and suicidal ideation. In the studies reported in this review, girls with higher scores on aggression reported elevations on depression at a rate close to $40 \%$. More than for boys, when girls behave violently, it is important to assess for the presence of underlying mental health disorder that may be coinciding with a higher violence potential. In addition, this review also identified rates in girls relative to boys who are aggressive as significantly higher reflected in diagnoses of ADHD, substance abuse, and suicide risk (Leschied, Cummings, Van Brunschot,

Canadian Research Perspectives for Youth at Risk for Serious and

Violent Offending: Implications for Crime Prevention Policies and Practices 
International Journal of Child, Youth and Family Studies (2011) 2.1: 233-262

Cunningham, \& Saunders, 2001).

Why might this be the case for girls experiencing higher rates of mental health disorder who express violence? One suggestion is that girls are at a much higher risk for being victimized physically or sexually in both their families of origin as well as through stranger contact, a fact that relates prior victimization with the perpetration of violence. Both Langhinrichsen-Rohling and Neidig (1995) and Watts and Ellis (1993) noted the association of a history of victimization for girls with higher scores on measures of violence and mental health indicators. Cunningham and Leschied (1998) reported the high incidence of victimization of women who subsequently came into contact with the adult justice system in part as a result of their past victimization histories. This cycle of victimization leading to aggression with adolescent girls is an obvious area for further study. Sibylle Artz (1998) of the University of Victoria suggests that, in part, aggression for girls may be viewed as a means of avoiding subsequent revictimization.

\section{Cycle of Violence}

An appreciation of the literature related to the cycle of violence and mental health disorder in children and youth is warranted. This reflects the data indicating that child victims of maltreatment - be it physical or sexual maltreatment, neglect, or exposure to interparental violence - are linked to later violent offending by children and youth. Two factors are of importance in this discussion. The first relates to the incidence of mental health disorder in children and youth who emerge from early family conditions where they are exposed to, or are the victims of violence. Second, the introduction to violence at an early age for many children is itself a risk factor for later violent offending.

Children who experience maltreatment are nearly twice as likely to report clinically significant elevations for emotional and behavioural disorder on the Child Behaviour Checklist compared to children and youth who do not report maltreatment (Burns et al., 2004). And, as previously indicated in relation to gender, girls are more likely to be victimized through maltreatment, particularly through sexual maltreatment, with evidence suggesting that these young women will experience such sequale from victimization as depression, self-injurious behaviour, and suicide to a greater extent relative to males who are maltreated (Leschied et al., 2000). Widom and Maxfield (2001) also have noted that such victimization increases the prevalence of violent offending in particular for female victims.

Numerous studies have reported on the link between early experiences with violence in a child's family of origin and later aggression. In one sample of maltreated adolescents, 39\% of youth self reported as incurring at least one violent offence by late adolescence, with that percentage "slipping” to $29 \%$ by early adulthood (Smith, Ireland, \& Thornberry, 2005). Clearly, the legacy of child maltreatment is enduring in the context of ongoing violence. In addition, it is

Canadian Research Perspectives for Youth at Risk for Serious and

Violent Offending: Implications for Crime Prevention Policies and Practices 
International Journal of Child, Youth and Family Studies (2011) 2.1: 233-262

not only the impact of being maltreated that for certain children and youth translates into their own perpetration of violence, but it is also the vicarious trauma experienced by children and youth in being exposed to interparental violence that influences that likelihood. Widom (1997) reported that witnessing verbal hostility and physical violence for children and adolescents was associated with higher levels of both internalizing and externalizing disorders, concluding that children who experience such exposure "[some children] developed post-traumatic stress disorder whereas others became angry and violent.”

\section{Cognitive and developmental correlates of youth violence}

This review was asked to speak to the literature relating the potential for violence in the context of cognitive and developmental anomalies.

Developmental disabilities. Hassan and Gordon (2003) suggest that “developmentally disabled people may be more likely than non-developmentally disabled people to exhibit characteristics, or experience social or economic conditions that have been associated with criminality such as low self-esteem, poverty and lack of social skills.” Early studies have also reported that developmentally disabled adult males were five times more likely, and females 25 times more likely, to commit a violent act than their non-developmentally disabled counterparts (Hodgins, 1992). There is little data, however, upon which to draw to investigate the relationship between developmentally disabled youth and the committal of violence. Most of the research in this area relates to the developmentally disabled being the victim rather than the perpetrator of violence. And typically, this victimization is related to sexualized violence. Only tangentially, the literature related to IQ does suggest that intelligence is a protective factor in crime generally and this holds true for violence as well.

Fetal Alcohol Spectrum Disorder. Fetal alcohol spectrum disorder (FASD) is the current diagnostic classification used to characterize children who have previously been referred to under various categories such as fetal alcohol syndrome (FAS), fetal alcohol effects (FAE) and prenatal exposure to alcohol (PAE). In a summary provided by Henry, Sloane, and Black-Pond (2007), the effects of FASD are described as:

prenatal alcohol exposure... impacts two core developmental processes neurophysiological growth of the brain, nervous system, and endocrine system, along with psychosocial development, including personality formation, social conduct, and capacity for relationships. Developmental domains affected include language, social cognition and communication, impulse control, memory, attention, and executive functioning.

Estimates for prevalence rates for FASD range from 3 to 190 per 1,000, with an

Canadian Research Perspectives for Youth at Risk for Serious and

Violent Offending: Implications for Crime Prevention Policies and Practices 
International Journal of Child, Youth and Family Studies (2011) 2.1: 233-262

estimated rate of 9 per 1,000 in Canada (Mills, McLennan, \& Caza, 2006). Along with the acknowledgement of severe developmental anomalies for children and youth experiencing FASD, and relevant to the current focus on mental health disorder and violence, is the data indicating the high prevalence of mental health disorder within this group as well. Mills et al. (2006) noted that between 93\% and 96\% of FASD children to the age of 9 years had comorbidity rates with mental health disorder, and as children with FASD age, the prevalence of comorbidity and mental health disorder actually increases. The most common forms of mental health disorder include sleep disorders, abnormal habits, and emotional disorders. The rates for FASD children with mental health disorders is typically twice the rate reported for children with other developmental anomalies such as ADHD (Mills et al., 2006). Of relevance to this discussion of violence and FASD is further evidence that these young people are also more likely to be the victims of violence. Streissguth, Barr, Kogan, and Bookstein (2002) noted that,

Violence against individuals with FAS/FAE occurred at an alarming rate: $72 \%$ had experienced physical or sexual abuse or domestic violence. Being a victim of violence was a strong risk factor for [these children and adolescents] committing inappropriate sexual behavior, increasing the odds fourfold.

The relevance of such data cannot be underscored too greatly. These young people not only possess developmental challenges in most all major cognitive spheres and share much higher representation in mental health categories, but their secondary disabilities related to interpersonal difficulties and consequent victimization also places them at greater risk for perpetrating violence as well. In a recent study on Aboriginal youth in western Canada, many of whom were diagnosed with FASD, violent reoffending rates along with sexual offending behaviour were much higher than in a comparable group of non-FASD youth. The suggestion is that cognitive deficits set the stage for low impulse control along with difficulties in social development and, along with a history of prior victimization, places these young people at greater risk for violence perpetration.

\section{An overview of best and promising practice interventions in youth violence and mental health disorder}

Two general concepts related to intervention follow from this review:

First, the relationship between mental health and youth violence is, for the most part, bidirectional. That is, child and youth violence victimization, be it either as a result of family-based maltreatment or peer on peer violence (e.g., school-based violence), has the effect of (a) increasing the likelihood a child or youth will reflect some form of mental health disorder, and (b) the presence of a mental health disorder in turn increases the risk that a child or youth will act out violently. Hence as a general statement, interventions that address mental health disorders in

Canadian Research Perspectives for Youth at Risk for Serious and

Violent Offending: Implications for Crime Prevention Policies and Practices 
International Journal of Child, Youth and Family Studies (2011) 2.1: 233-262

children and youth will have the effect of reducing the risk for violence within this population as well.

Second, there are general principles regarding effective interventions for children and youth that translate to the literature on violence prevention and intervention. These general principles can guide the selection and implementation of effective services to reduce youth violence (see Farrington, 2001; Farrington \& Welsh, 2007). These intervention strategies include:

Services are targeted. Capitalizing on the knowledge base addressing the links between mental health disorder and youth violence, effective services will target the specific causes of youth violence and mental health.

Services are empirically-based. There is now an extensive body of knowledge in regard to effective service such that prevention and intervention strategies should be guided by the literature that has evaluated service outcomes.

Services reflect the multiple pathways that link mental health disorder and youth violence. As can be appreciated from the literature summarizing the links between mental health disorder and youth violence, there are numerous multiple causes that link mental health and violence and many of these are co-occurring. Interventions need to reflect the coincidental occurrence of a variety of risk factors within their intervention.

Services are gender-informed. The links between mental health disorders and violence are unique as a function of gender. In the summary related to risk factors associated with female violence, literature reflects that girls will more likely experience an underlying mental health disorder such as depression and suicidal ideation relative to boys. Interventions need to reflect this understanding.

Services are developmentally appropriate. More recent evidence with respect to effective service delivery in youth violence prevention and intervention indicates that for services to be effective, they need to reflect age appropriate services that connect meaningfully with the children and youth who are the receivers of that service. In addition, age appropriate service also reflects appropriately targeted service in the context of when the risk occurs. For example, children victimized through maltreatment who then become violent will benefit from services differentially compared to adolescents who are the victims of maltreatment and show violence.

Service implementation constitutes a "science" in its own right. It is a necessary but not

Canadian Research Perspectives for Youth at Risk for Serious and 
International Journal of Child, Youth and Family Studies (2011) 2.1: 233-262

sufficient condition to select empirically-based services. Services, in order to be effective, need also to be implemented in ways consistent with the principles of effective service delivery (See Bernfield, Farrington, \& Leschied, 2001).

As aforementioned, there is a well-established empirically-based literature reporting on outcomes related to violence prevention and intervention now being reported. As a caveat to this summary, the extensive literature on best and promising approaches to the reduction of youth violence tends to follow the above five principles. Hence within a brief overview of this literature summary, only a snapshot of effective service is provided. What it will reflect is the variety of programs being reported, what they target, and where they are offered.

Services that focus on primary prevention. Primary prevention programs target the onset of violence. A useful example of this form of intervention focuses on the effects of media violence. While not as extensively evaluated as other forms of violence prevention, strategies that reduce a child or youth's exposure to media violence, such as the introduction of technology to control violence displays through the $\mathrm{V}$-chip and coding for content of video games similar to what is used in movies, are examples of primary prevention. Such technology empowers caregivers to monitor their child's intake of violence from the media, particularly for those children who may be more susceptible to its influence. These susceptibilities will include children and youth who have experienced trauma linked to previous violence exposure or who already demonstrate vulnerability to media violence due to a pre-existing emotional disorder. More direct forms of prevention would also include the Ontario Ministry of Education's promotion of courses on media literacy within the elementary grades. One such example is the Ontario Ministry of Education's Media literacy resource guide. There are also findings from the family intervention literature that have shown encouraging outcomes in promoting more effecting parenting and a lowering of risk among children. These would include the Triple "P" Parenting and COPE programs along with Ontario’s Better Beginnings, Better Futures and Best Start Programs.

Services that focus on secondary prevention. Secondary prevention programs target the risks and needs of youth who have already developed the risk for violence but who have as yet not displayed aggressive or violent behaviour. This group of interventions will include targeting children and youth who already display such risk factors as a history of maltreatment, or victimization through dating violence. Examples in this category include programs that are directed at abuse survivors, which assist in helping youth victims with post-traumatic stress disorder, feelings of vulnerability, depression, and suicidality. The work of Leena Augimeri and her colleagues at Toronto's Child Development Institute in delivering the SNAP (Stop Now and Plan) program falls into this category of effective programs that target children under the age of 12 years (Augimeri, Farrington, Koegl, \& Day, 2007).

Canadian Research Perspectives for Youth at Risk for Serious and Violent Offending: Implications for Crime Prevention Policies and Practices 
International Journal of Child, Youth and Family Studies (2011) 2.1: 233-262

Services that target tertiary prevention. Tertiary prevention programs are directed at those youth who have already been identified as being at risk and have committed acts of violence. Gang interventions serve as useful examples of this level of intervention. Effective services in this area include: targeting youth's need for mentoring; focused skill development; the teaching of non-violent conflict resolution skills; substance and alcohol abuse intervention programs; academic and vocationally focused upgrading and recreation programs.

Services that are community-based. Community-based services are, as they refer, programs that occur within the youth's community and require implementation on a communitywide coordinated basis. The work of Scott Henggeler and his colleagues through the Medical University of South Carolina is singular in evaluating and reporting on effective communitywide efforts to reduce adolescent violence (Swenson et al., 2005). The components of MST service in reducing youth violence are well chronicled in numerous studies and reports. MST is considered as one of the best practice programs as reported by the highly regarded Washington State Institute for Public Policy (WSIPP) and The Center for the Study and Prevention of Violence at the University of Colorado.

Services located within schools. School-based violence prevention and intervention programs are widely implemented as part of almost every school board's initiatives to reduce not only violence that occurs within the school but also targets the factors that could help generalize to violence reduction within the broader community. A number of programs report on providing successful conflict resolution skills for youth. One notable program that is currently being evaluated is the "Fourth 'R' Project” (Wolfe, 2011) offered through the Centre for Prevention Science, Centre for Addiction and Mental Health. This project provides a curriculum-based, teacher offered program that focuses on the development and building of relationship capacity within the general elementary and secondary school-age populations with the primary outcome being the ability for youth to display non-violent conflict resolution skills.

\section{Limitations in the research on youth violence}

While the literature with respect to youth violence is substantial, it carries with it the caveats of most all applied research in being limited by the research designs and methods employed. Most of the work reported here is retrospective and correlational in nature, and hence the limitations with respect to causality are always in evidence when it comes to interpretation. Although, within all lines of research that rest on correlational studies, interpretation of outcomes rest on convergence through replication. With respect in particular to the knowledge base in risk predication for youth violence, outcomes from the major longitudinal studies by David Farrington in the United Kingdom and Rolf Loeber in the United States report high levels of agreement with much of the cross-sectional, retrospective findings, thereby adding credence to

Canadian Research Perspectives for Youth at Risk for Serious and

Violent Offending: Implications for Crime Prevention Policies and Practices 
International Journal of Child, Youth and Family Studies (2011) 2.1: 233-262

the risk predictors for youth violence that are reported in this review. In addition, some of the findings from Canadian-based longitudinal studies by Richard Tremblay and Marc LeBlanc, although not as robust in comparison to Farrington and Loeber, are supportive of the knowledge base in youth violence and risk.

As well, this review focused on the nature of co-morbidity relating mental health disorders and violence in children and youth. As will be apparent in reading this literature, it is often difficult to disentangle the what and when of these two factors of risk for children and youth. This was no more apparent than in the review related to child maltreatment and the cycle of violence. Exposure to family violence for children, either through vicarious trauma of witnessing violence or being the victim of maltreatment sets the stage for the development of both higher reported rates of emotional disorder (i.e., depression) and acting out the violence. The "pathway" leading from the exposure to violence to the child or adolescent acting violently themselves is unclear yet a relevant area of investigation. The literature related to substance use and violence, in contrast, has matured to the point where path analyses - predicting the strength and direction of the relationship between these two events and the outcome - are well established. Charting the relationship between mental health status and aggression in children and youth would similarly benefit from investigations of this type.

\section{Future Directions for Research}

Currently there is unprecedented worldwide interest in research addressing youth violence. And, there is urgency in developing our understanding regarding how we can be more effective in providing services and interventions that can lessen the risk for violence. The World Health Organization reports that worldwide, "36.2\% of global mortality due to interpersonal violence occurred among young adults aged 15-29 years ... and for every youth's death that occurs from interpersonal violence, many more young people are injured and permanently disabled" (World Health Organization, 2007). The Packard Foundation's report in the United States, Children, Youth and Gun Violence, indicates that gun violence in the United States is the second leading cause of death in young people ages 10 to 19, accounting for the deaths of 20,000 children (Behrman, 2002). In Ontario, the death of Toronto's Jane Creba on Boxing Day, 2006 and Jordan Manners at C.W. Jefferies School remind us we are not immune to realizing the effects of youth violence. While Ontario's concern for youth violence may not seem similar in degree or lethality to other parts of the world, Ontario does share a high degree of similarity in interests in worldwide research initiatives to address youth violence. This section will outline those research areas that could best advance our understanding of youth risk and effective services.

\section{Research focusing on understanding youth risk}

Canadian Research Perspectives for Youth at Risk for Serious and

Violent Offending: Implications for Crime Prevention Policies and Practices 
International Journal of Child, Youth and Family Studies (2011) 2.1: 233-262

Promoting a developmental understanding related to risk, mental health disorder, and youth violence. A review of the most important contributions in the past several years to understanding both risk and effective interventions has highlighted the area of "charting" the pathway of child and youth experiences that lead to violence. This approach to understanding risk builds on the empirical basis of risk prediction, with the value-added component of casting it within a developmental framework. LeBlanc and Loeber’s (1998) updated contribution to developmental criminology suggests that "It is important to search for variables that determine or mediate the variation of behavior with age [as it relates to violence potential]". Such research contributions would improve our understanding of which services offered in the timeliest ways could reduce risk for youth violence. This line of research would most significantly inform services in the area of secondary prevention. David Farrington's two recent summaries have helped focus research efforts in intervention in the context of developmental pathways to violence. In Ontario, The work of Christine Wekerle and the Maltreatment Adolescent Pathways (MAP) project reflects this type of research and will provide significant contributions in this area.

Resilience and protective factors for youth who reside in high-risk communities. While much is known about risk factors with children and youth that are related to violent offending, considerably less is known about the conditions that influence heretofore higher risk cases becoming lower risk. For example, while there is considerable information related to macro level risk indicators such as poverty and neighbourhood stability, it remains an accepted fact that the majority of children and youth even in these highest of risk communities do not resort to violence. Research that addresses invulnerability within this group of youth would be a very significant contribution in helping communities mobilize naturally occurring conditions that promote resiliency within the community.

Developmental disabilities and FASD services. While children and youth who experience developmental disabilities and FASD are low relative to the frequency they appear within the youth population, they do in themselves represent very high-risk groups in regard to violence. Yet, there is a lack of studies reporting on effective ways of managing their considerable needs. One exception to this is the prevention strategies to reduce alcohol consumption in expectant mothers in reducing the incidence of FASD. However even here, few studies report on the impact of these prevention efforts to reduce FASD. More research is required to understand the needs of these youth and their families in developing strategies that can reduce their violence potential.

\section{Research promoting the understanding of delivering effective services}

Gender-informed programming in youth violence. It has only been within the past 10 years that a research agenda in Canada has begun to inform service providers regarding the

Canadian Research Perspectives for Youth at Risk for Serious and

Violent Offending: Implications for Crime Prevention Policies and Practices 
International Journal of Child, Youth and Family Studies (2011) 2.1: 233-262

differential understanding of female violence in relation to male violence. Previously, what was known regarding the models of violence that youth interventions were built on, reflected our understanding of how males acted violently, not females. As this gender-informed appreciation has developed regarding risk and violence, programs have developed to reflect this orientation, services that are unique and tailored to the individual needs of girls. However, these programs are to a large extent still in their infancy, and service providers are only now integrating genderinformed components into their violence prevention and intervention strategies. Outcome research needs to both focus of how these services are meeting the needs of girls and what kinds of outcomes can be achieved. This is of particular relevance in the context of mental health. This review has identified that girls involved in violence report much higher comorbidity rates of emotional disorder and violence.

Effective coordination of various service sectors in targeting youth violence. All studies that focus on community-wide efforts in reducing youth violence speak to interventions that range from mental health specific, to academic, vocational, and social skills targets within a group of youth. Such coordinated efforts at intervention require the cooperation of a variety of service providers. Yet, these same studies reporting on the need for coordinated service efforts all speak to the difficulties in providing focused, coordinated, and timely services such that treatment outcomes can be maximized. Research into service delivery needs to advance our understanding regarding what the most effective means are to provide such cross-sectoral services. This research will be of particular relevance for communities who are examining the delivery of gang-focused services where youth needs are diversified and require coordinated community efforts.

Service delivery issues related to offering best practices in violence prevention and intervention. This review identified that the implementation of effective service should be considered as a science in its own right. That is, while the literature is growing regarding what services are most effective, less is known about how to generalize the delivery of those services such that high levels of replication can report similar positive outcomes across all communities. Questions related to the required training of those delivering the service, when services should be offered (i.e., daytime, evening, weekends), and how intensive services need to be to achieve positive outcomes, are examples of areas requiring further investigation. One way to address this gap in the literature is to study those programs that have demonstrated positive outcomes in relation to mental health and violence and examine the conditions under which the programs were successively developed and delivered.

Effective means of disseminating the existing information regarding current best practice research in youth violence. There is a considerable body of evidence that speaks to understanding the needs of children and youth who experience both mental health concerns and who are also at risk for violence. In addition, there is a growing research literature on effective

Canadian Research Perspectives for Youth at Risk for Serious and

Violent Offending: Implications for Crime Prevention Policies and Practices 
International Journal of Child, Youth and Family Studies (2011) 2.1: 233-262

services that reduce risk. And, while numerous gaps in our knowledge still remain, perhaps the largest gap of all is that between the knowledge that exists and the service providers who are charged with implementing the program. The challenge therefore is this: How do we disseminate and translate this evidence such that communities and service providers can utilize this knowledge in informing their approaches to meet the needs of youth and their communities? There is little information to inform the best strategies to connect knowledge with its potential users. Evaluating effective strategies to disseminate the existing research knowledge should be considered a high priority.

\section{Summary}

This review underscores the extent of the knowledge base for youth with respect to violence and mental health. The importance of focusing efforts to both further our understanding regarding those children and youth who are at risk for being aggressive and those interventions that can lessen that risk are considerable. The most likely victim of youth violence is another youth. Hence, what we know about the cycle of violence and mental health is that once victimized, those children then increase their own likelihood of developing similar disorders that compromise the community's safety with respect to further victimization. Drawing on our knowledge with respect to effective outcomes, from prevention through to tertiary intervention, has a significant payoff in lessening the traumatic effects on both the direct victims as well as the general community. There is also current research efforts focused on accounting for the "cost" of purchasing community safety; cost as measured both in terms of lessening human misery

through reduced victimization rates, as well as in real economic costs related to "purchasing" the benefits of delivering effective services to youth at risk. Aos, Lieb, Mayfield, Miller, and Pennucci (2004) summarize their considerable findings thusly:

In the last two decades, research on what works and what doesn't has developed and, after considering the comparative economics of these options, this information can now be used to improve public resource allocation [in an effort to reduce youth violence].

Clearly when we look to research in this area to help guide our efforts, there is much to inform our decisions that benefits all who are concerned with reducing youth violence and mental health disorders, thereby improving community safety.

Canadian Research Perspectives for Youth at Risk for Serious and 
International Journal of Child, Youth and Family Studies (2011) 2.1: 233-262

\section{References}

Anderson, C. A., Berkowitz, L., Donnerstein, E., Huesmann, L. R., Johnson, J. D., Linz, D., et al. (2003). The influence of media violence on youth. Psychological Science in the Public Interest, 4(3), 81-110.

Aneshenel, C. S., \& Sucoff, C. A. (1996). The neighborhood context of adolescent mental health. Journal of Health and Social Behavior, 37(4), 293-310.

Artz, S. (1998). Where have all the school girls gone? Violent girls in the school yard. Journal of Child and Youth Care, 11(2), 17-37.

Arsenault, L., Moffitt, T. E., Caspi, A., Taylor, P. J., \& Silva, P. A. (2000). Mental disorders and violence in a total birth cohort. Archives of General Psychiatry, 57(10), 979-986.

Aos, S., Lieb, R., Mayfield, J., Miller, M., \& Pennucci, A. (2004). Benefits and costs of prevention and early intervention programs for youth. Olympia, WA: Washington State Institute for Public Policy.

Augimeri, L. K., Farrington, D. P., Koegl, C. J., \& Day, D. M. (2007). The Under 12 Outreach Project: Effects of a community based program for children with conduct problems. Journal of Child and Family Studies, 16, 799-807. Published Online, January 10, 2007. DOI: 10.1007/s10826-006-9126-X

Behrman, R. (Ed.). (2002). The future of children: Children, youth and gun violence. Los Altos, CA: The Packard Foundation.

Bernfeld, G. A., Farrington, D., \& Leschied, A. W. (Eds.). (2001). Offender rehabilitation in practice: Implementing and evaluating effective programs. London: John Wiley Press.

Bjorkqvist, K., Osterman, K., \& Kaukiainen, A. (1992). The development of direct and indirect aggressive strategies in males and females. In K. Bjorkqvist \& P. Niemela (Eds.), Of mice and women: Aspects of female aggression (pp. 51-64). San Diego: Academic Press Inc.

Borduin, C. M., \& Schaeffer, C. M. (1998). Violent offending in adolescence: Epidemiology, correlates, outcomes and treatment. In T. P. Gulotta, G. R. Adams, \& R. Montemayor (Eds.), Delinquent violent youth: Theory and interventions (pp. 144-174). Thousand Oaks, CA: Sage Publications. 
International Journal of Child, Youth and Family Studies (2011) 2.1: 233-262

Burns, B., Phillips, S. D., Wagner, H. R., Barth, R., Kolko, D., Campbell, Y., et al. (2004). Mental health need and access to mental health services by youths involved with child welfare: A national survey. Journal of the American Academy of Child and Adolescent Psychiatry, 43(8), 960-970.

Canadian Centre on Substance Abuse. (2007). Substance abuse in Canada: Youth in focus. Ottawa, ON: Author.

Cunningham, A., \& Leschied, A. W. (1998). Thinking about choices: Program recommendations for women in conflict with the law with histories of abuse victimization. Hamilton, ON: Elizabeth Fry Society of Hamilton-Wentworth and Correctional Services Canada.

Crick, N. R. (1996). The role of overt aggression, relational aggression, and prosocial behavior in the prediction of children's future social adjustment. Child Development, 67(5), 2317-2327.

Cummings, A., \& Leschied, A. W. (Eds.). (2002, Fall). Violence in the lives of adolescent girls: Implications for educators and counsellors. New York: Edwin Mellen Press.

Durant, R. H., Barkin, S., Kreiter, S. R., \& Krowchuk, D. P. (2001). Exposure to violence and victimization, depression, and substance use and the committal of violence in young adolescents. Adolescent Medicine, 45, 4-13.

Dishion, T. J., Capaldi, D. M., \& Yoerger, K. (1999). Middle childhood antecedents to progression in male adolescent substance use: An ecological analysis of risk and protection. Journal of Adolescent Research, 14(2), 175-207.

Everett, S. A., \& Price, J. H. (1995). Students' perceptions of violence in the public schools: The Metlife survey. Journal of Adolescent Health, 17(6), 345-352.

Farrington, D. P. (Ed.). (2001). Integrated developmental and life course theories of offending. London: Transaction Publishers.

Farrington, D. P., \& Welsh. B. (2007). Saving children from a life of crime: Early risk factors and effective interventions. New York: Oxford University Press.

Findlay, J. (2002). Cross-over kids. Toronto: Ontario Office of the Child Advocate.

Gilgan, J. F. (1999). Detecting the potential for violence. Minneapolis: Minnesota Center Against Violence and Abuse and the University of Minnesota. 
International Journal of Child, Youth and Family Studies (2011) 2.1: 233-262

Goodman, S. H., Hoven, C. W., Narrow, W. E., Cohen, P., Fielding, B., Alegria, M., et al. (1998). Measurement of risk for mental disorders and competence in a psychiatric epidemiologic community survey: The National Institute of Mental Health methods for the epidemiology of child and adolescent mental health disorders (MECA) study. Social Psychiatry and Psychiatric Epidemiology, 33(4), 162-173.

Gover, A. R. (2004). Risky lifestyles and dating violence: A theoretical test of violent victimization. Journal of Criminal Justice, 32(2), 171-180.

Hassan, S., \& Gordon, R. M. (2003). Developmental disability, crime, and criminal justice: A literature review. Burnaby, BC: Simon Fraser University.

Hawkins, J. D., Herrenkohl, T., Farrington, D. P., Brewer, D. D., Catalano, R. F., \& Harachi, T. W. (1998). A review of predictors of youth violence. In R. Loeber \& D. P. Farrington (Eds.), Serious and violent juvenile offenders: Risk factors and successful interventions (pp. 106-146). London: Sage Publications.

Hawkins, J. D., Herrenkohl, T. I., Farrington, D. P., Brewer, D., Catalano, R. F., Harachi, T. W., \& Cothern, L. (2000). Predictors of youth violence. Washington, DC: Office of Juvenile Justice and Delinquency Prevention.

Heng, C. L., Leschied, A., \& Killip, S. (2009). Violence in schools: Examining the differential impact of school climate on student's coping ability. Education and Law Journal, 19(2), 95-118.

Henington, C., Hughes, J. N., Cavell, T. A., \& Thompson, B. (1998). The role of relational aggression in identifying aggressive boys and girls. Journal of School Psychology, 36(4), 457-477.

Henry, J., Sloane, M., \& Black-Pond, C. (2007). Neurobiology and neurodevelopmental impact of childhood traumatic stress and prenatal alcohol exposure. Language, Speech, and Hearing Services in Schools, 38(2), 99-108.

Hodgins, S. (1992). Mental disorder, intellectual deficiency, and crime: Evidence from a birth cohort. Archives of General Psychiatry, 49(6), 476-485.

Huesmann, L. R., Moeski , J. F., \& Podolski, C. L. (1997). The effects of media violence on the development of antisocial behavior. In D. M. Stoff, J. Breiling, \& J. D. Maser (Eds.), Handbook of antisocial behaviour. Chichester, UK: John Wiley and Sons.

Huizinga, D. H., Menard, S., \& Elliott, D. S. (1989). Delinquency and drug use:

Canadian Research Perspectives for Youth at Risk for Serious and 
International Journal of Child, Youth and Family Studies (2011) 2.1: 233-262

Temporal and developmental patterns. Justice Quarterly, 6(3), 419-455.

Ladd, G. W., Buhs, E. S., \& Troop, W. (2002). Children’s interpersonal skills and relationships in school settings: Adaptive significance and implications for school-based prevention and intervention programs. In P. K. Smith \& C. H. Hart (Eds.), Blackwell handbook of childhood social development (pp. 394-215). London: Blackwell Publishers Ltd.

Lafontaine, T., Ferguson, M., \& Wormith, J. S. (2005). Street gangs: A review of the empirical literature on community and corrections-based prevention, intervention and suppression strategies. Regina: University of Saskatchewan.

Langhinrichsen-Rohling, J., \& Neidig, P. (1995). Violent backgrounds of economically disadvantaged youth: Risk factors for perpetrating violence? Journal of Family Violence, 10(4), 379-397.

LeBlanc, M., \& Loeber, R. (1998). Developmental criminology updated. Crime and Justice, 23, 115-198.

Leschied, A. W. (2007). Effective programming in Ontario youth justice: The challenge posed by gangs, reintegration from custody to community and short terms stays in custody. Toronto: Ministry of Children and Youth Services.

Leschied, A. W., Chiodo, D., Nowicki, E., \& Rodger, S. (2008). Childhood predictors of adult criminality: A meta analysis. Canadian Journal of Criminology and Criminal Justice, 50(4), 435-468.

Leschied, A. W., Cummings, A., Van Brunschot, M., Cunningham, A., \& Saunders, A. (2000). Female adolescent aggression: A review of the literature and correlates (Solicitor General of Canada, User Report Number 9914-UNI-587). Ottawa: Queen’s Printer.

Leschied, A. W., Cummings, A. L., Van Brunschot, M., Cunningham, A., \& Saunders, A. (2001). A review of the literature on aggression in adolescent girls: Implications for policy, prevention and treatment. Canadian Psychology, 42(3), 200-215.

Leschied, A. W. (2007). Evidence as a guide: Implementation of Ontario's youth gang policy. Toronto: Ministry of Children and Youth Services.

Lipsey, M. W., \& Derzon, J. H. (1998). Predictors of violence or serious delinquency in adolescence and early adulthood: A synthesis of longitudinal research. In R. Loeber \& D. P. Farrington (Eds.), Serious and violent juvenile offenders: Risk factors and successful interventions (pp. 86-105). London: Sage Publications.

Canadian Research Perspectives for Youth at Risk for Serious and 
International Journal of Child, Youth and Family Studies (2011) 2.1: 233-262

MacKay, A. W., \& Sutherland, L. C. (2006). Teachers and the law. Toronto: Emond Montgomery Publications Limited.

MacKinnon-Lewis, C., Kaufman, M. C., \& Frabutt, J. M. (2002). Juvenile justice and mental health: Youth and families in the middle. Aggression and Violent Behavior, 7(4), 353-363.

Mandell, D. J., Hill, S. L., Carter, L., \& Brandon, R. N. (2002). The impact of substance use and violence on academic achievement for groups of middle and high school students in Washington. Seattle, WA: Kids Count Human Services Policy Centre.

Mills, R. M., McLennan, J. D., \& Caza, M. M. (2006). Mental health and other service use by young children with fetal alcohol spectrum disorder. Journal of Fetal Alcohol Syndrome, 4, 1-11.

Molidor, C., \& Tolman, R. M. (1998). Gender and contextual factors in adolescent dating violence. Violence Against Women, 4(2), 180-194.

Monahan, J. (1997). Major mental disorders and violence to others. In D. M. Stoff, J. Breiling, \& J. D. Maser (Eds.), Handbook of antisocial behavior (pp. 92-100). Chichester, UK: John Wiley and Sons.

National Center for Educational Statistics. (2005). Indicators of school crime and safety: 2005. Washington, DC: U.S. Department of Education.

Offord, D., Boyle, M. H., Fleming, J. E., Blum, M., \& Rae-Grant, N. I. (1989). Ontario child health study: Summary of selected results. Canadian Journal of Psychiatry, 34(6), 483-491.

Osenblatt, A. (2001). An overview of mental health and children. San Francisco: The University of California, San Fransisco.

Patterson, G. R., Reid, J. B., \& Dishion, T. J. (1992). Antisocial boys. Eugene, OR: Castalia.

Rigby, K. (2003). Consequences of bullying in schools. The Canadian Journal of Psychiatry, 48(9), 583-590.

Reynolds, W. (2003). Reynolds bully victimization scales for schools - Manual. San Antonio, TX: PsychCorp.

Rusby, J. C., Forrester, K. K., Biglan, A., \& Metzler, C. W. (2005). Relationships 
International Journal of Child, Youth and Family Studies (2011) 2.1: 233-262

between peer harassment and adolescent problem behaviours. Journal of Early Adolescence, 25(4), 453-477.

Smith, C. A., Ireland, T. O., \& Thornberry, T. P. (2005). Adolescent maltreatment and its impact on young adult antisocial behavior. Child Abuse and Neglect, 29(10), 1099-1119.

Silverman, J. G., Raj, A., Mucci, L. A., \& Hathaway, J. E. (2001). Dating violence against adolescent girls and associated substance use, unhealthy weight control, sexual risk behavior, pregnancy, and suicide. Journal of the American Medical Association, 286(5), 572-579.

Swenson, C. C., Henggeler, S., Taylor, I. S., \& Addison, O. W. (2005). Multisystemic therapy and neighborhood partnerships: Reducing adolescent violence and substance abuse. New York: The Guildford Press.

Streissguth, A., Barr, H., Kogan, J., \& Bookstein, F. (2002). Primary and secondary disabilities in fetal alcohol syndrome. In A. Streisssguth \& J. Kanter (Eds.), The challenge of fetal alcohol syndrome: Overcoming secondary disabilities (pp. 2539). Seattle, WA: University of Washington Press.

Teplin, L. A., Abram, K. M., McClelland, G. M., Dulcan, M. K., \& Mericle, A. A. (2002). Psychiatric disorders in youth in juvenile detention. Archives of General Psychiatry, 59(12), 1133-1143.

Warner, B. S., Weist, M. D., \& Krulak, A. (1999). Risk factors for school violence. Urban Education, 34(1), 52-68.

Watts, D. W., \& Ellis, A. M. (1993). Sexual abuse and drinking and drug use: Implications for prevention. Journal of Drug Education, 23(2), 183-200.

Widom, C. (1997). Child abuse, neglect, and witnessing violence. In D. M. Stoff, J. Brieling, \& J. D. Maser (Eds.), Handbook of antisocial behaviour (pp. 159-170). Chichester, UK: John Wiley and Sons.

Widom, C., \& Maxfield, M. G. (2001). An update on the cycle of violence. Washington, DC: National Institute of Justice.

Wolfe, D. A. (2011). The Fourth ' $R$ ' project. London, ON: CAMH http://www.thefourthr.ca

World Health Organization. (2007). Youth violence. Kincardine, Scotland: Author. 